\title{
CHALLENGES IN CLIMATE CHANGE ECONOMICS
}

\section{Frederick van der Ploeg ${ }^{1}$ and Cees Withagen ${ }^{2}$}

Economists have long argued that the best way to fight climate change is to levy a price on carbon emissions, either via a global specific carbon tax or a competitive worldwide market for emission permits. This price should be Pigouvian and equal the present value of current and future global warming damages and be the same throughout the world. Despite decades of climate negotiations, very little success has been achieved in implementing such first-best climate policies. This disappointing cleavage between theory and practice poses three important challenges to economists. First, global warming is the only truly global externality and therefore policy makers are confronted with huge free riding problems and countries choosing to protect jobs in fossil-based industries at home in favour of protecting the planet (such as the United States under President Trump). International climate agreements do not cover all countries of the world. So if only some countries price carbon, this will depress the world price of coal, oil and gas and thus some of the cuts in emissions will be offset by higher emissions elsewhere. These carbon leakage problems can be overcome to an extent by border tax adjustments or so-called "climate clubs" that punish third non-participating countries with a stiff trade tariff of around 5\% (Nordhaus, 2015). Second, most politicians have a tendency to procrastinate and postpone carbon pricing so that their successors have to deal with the unpopular task of fighting climate change. Politicians also prefer the "stick" to the "carrot" and therefore choose to give huge renewable energy subsidies and green R\&D subsidies instead of pricing carbon. Although such policies work eventually in locking up more carbon in the crust of the earth, they waste public money and induce rent seeking. Furthermore, both postponing climate policy and subsidising renewable energy induces coal, oil and gas producers to exhaust their reserves more quickly and thus to accelerate carbon emissions and global warming. These Green Paradox effects thus add on to the carbon leakage effects. As far as financial markets are concerned, there is a risk of stranded financial assets to do with irreversible investments if policy makers suddenly take credible and effective action to fight global warming. Third, the energy transition towards a carbon-free economy requires huge technological innovations.

This special issue collects some of the papers that were presented at the conference "Combating Climate Change, Lessons from Macroeconomics, Political Economy and Public Finance” held April 22-23 2016 at Tinbergen Institute Amsterdam and that deal with these types of challenges.

\footnotetext{
${ }^{1}$ University of Oxford, Manor Road, Oxford OX1 3UQ, U.K. Also affiliated with St. Petersburg State University, 7/9 Universitetskaya nab., St. Petersburg, 199034 Russia, and VU University Amsterdam.

${ }^{2}$ IPAG Business School Paris and VU University Amsterdam.
} 
Much of the empirical work that has been done has attempted to quantify the impact of climate change on the economy, and in particular the damages of global warming to world GDP which are necessary to calculate the worldwide social cost and price of carbon. But it must be remembered that such worldwide estimates are derived from a bottom-up approach of estimating damages at the local level. Local impact studies and especially those addressing what can be done at a local level to adapt to the impact of global warming, are important. Climate services include providing information on climate change to the general public or specific users. Such services can be crucial, in particular for agriculture. One specific example concerns coffee farming. Growth of coffee plants is threatened by coffee rust, which is highly dependent of weather conditions and which can only be prevented if timing is accurate, not too late and not too early. Filippo Lechtaler's and Alexandra Vinogradova's published article "The climate challenge for agriculture and the value of climate services: Application to coffee-farming in Peru", which has been reprinted in this issue, addresses this problem (Lechthaler and Vinogradova, 2017). They constructed a theoretical model, to assess the value of climate services in general. They also described in much detail, the empirical value of climate services in the case of coffee farming in Peru, and showed that climate services are important for the design of climate adaptation strategies.

Two papers address the first challenge by modifying the standard approach to international environmental agreements. Ngo Van Long, Quentin Grafton and Tom Kompas in their "A brave new world? KantianNashian interaction and the dynamics of global climate change mitigation" challenge the Nash equilibrium concept as a way of modelling international negotiations on reductions in greenhouse gas emissions. This might explain why the countries of the European Union, various states of the United States, China, and other countries have taken initiatives to curb emissions. Their equilibrium concept revolves around the idea that a Kantian agent when contemplating to deviate from an action assumes that all other Kantian agents will follow. In their model there are also Nash-like agents and they show that the resulting equilibrium with perfect knowledge is Pareto-efficient.

Charles Mason, Stephen Polasky and Nori Tarui in their contribution "International agreements, climate change, differential games" also deal with the first challenge. They take account of the development over time of the stock of greenhouse gases when analysing the possibility of international climate agreements. They introduce a two-part dynamic punishing scheme: In stage one countries coordinate on an efficient abatement pattern; in stage two a country that has deviated from the equilibrium must curb its emissions whereas the other countries can boost their emissions for a prescribed period of time. If no deviations

\footnotetext{
${ }^{3}$ The articles by Borissov et al. (2017), Brock and Xepapdeas (2017) and Lechthaler and Vinogradova (2017) have been published in a regular issue of this journal, but were part of the conference, and therefore summarized here.
} 
have taken place during this prescribed period, countries cooperate at the end of it. Else, one enters again a punishment phase. It is shown that this punishing scheme leads to less global warming.

The published paper by Kirill Borissov, Mikhail Pakhnin, Clemens Puppe (Borissov et al., 2017) asks the question what rate of extraction of a renewable or exhaustible resource (say, oil) will be chosen by society? If emissions are a by-product of extraction and consumption of oil, then it is shown that in a voting equilibrium with agents differing in the rate of time preference emissions are determined by the median discount factor. This approach provides an opportunity to speculate about Stern-Nordhaus debate, or, more specifically, about Nordhaus's consumer sovereignty approach. According to Nordhaus, public and private investment should be evaluated with the same standards and hence the discount rate must be equal to the real interest rate. This argument is correct only if we assume a representative agent and therefore there is no problem with aggregating time preferences. If discount factors are heterogeneous, the problem of preference aggregation naturally arises.

Thomas Eichner and Rüdiger Pethig in their "Buy coal and act strategically" speak to the second challenge of convincing market participants to lock up coal, oil and gas reserves in the crust of the earth. They critically consider the seminal idea of a climate coalition buying up fossil fuel reserves from their owners put forward by Bård Hardstad in his article "Buy coal! A case for supply-side environmental policy" (Hardstad, 2012). They assume a world market for fossil fuel that is costly to extract. They consider two types of countries. Those that own fossil fuel deposits, do not sign international climate agreements and do not care about potential damages from carbon emissions; and countries that form an international climate coalition and care about climate change. The latter countries buy reserves in a certain range of extraction costs, entailing that the non-signatory countries will not exploit these resources (and these bought reserves will not be exploited at all by the buying countries). They show that, even with strategic behaviour of the signatories, this policy may be efficient. If it is not, a policy where the coalition might still exploit the reserves that have been bought makes the coalition better off.

In their published article "Climate change policy under polar amplification" (also reprinted in this issue), William Brock and Anastasios Xepapadeas discussed the first challenge of how to conduct a global climate policy when there are climatic differences across the planet (Brock and Xepapadeas, 2017). More precisely, they investigated the implications of polar amplification, which is the phenomenon that at high latitudes and especially at the poles average temperature change is higher than average overall temperature change. This has consequences for marginal damages in different regions of the planet and therefore also for optimal carbon taxes. They developed a two-region energy balance model that allows for calculating the optimal carbon tax in case of differential temperature increases and damages. Ignoring 
the polar amplification effect leads to an underestimation of the optimal tax with an associated welfare loss of $2 \%$ of steady state consumption.

Speaking of the second and the third challenge is that even though the cost of renewable energies is falling rapidly, there is a technological problem of storage. This is still the main obstacle to the large-scale introduction of solar and wind energy. Examples of energy storage are pumped hydro, compressed air storage and batteries. Itziar Lazkano, Linda Nostbakken and Martino Pelli in their investigation "From fossil fuel to renewables: The role of electricity storage" highlight that renewable energy technologies have made considerable progress, but that large-scale storage is crucial to make further gains. They address two interrelated questions. The first question is whether better storage opportunities have an impact on innovation in electricity generation with renewables as well as non-renewables. The second question is whether innovation in electricity generation leads to better storage technologies. Both questions are addressed in an empirical setting with 79 countries and for a period from 1963 till 2011. One of the outcomes is that better storage opportunities indeed enhance innovation in renewables technologies. But, maybe surprisingly, they also lead to innovation in conventional electricity production, because the producers are enabled to produce at a more constant rate. It is also shown that improved renewables technologies incentivise innovation in storage.

Hans-Werner Sinn in his keynote contribution "Buffering volatility: A study on the limits of Germany's energy revolution" discusses in detail several problems related to the German 'Energiewende' or energy revolution. This is an ambitious project that aims to cut $\mathrm{CO} 2$ emissions by $80 \%$ in 2050, compared to 1990, and to phase out nuclear energy by 2022 . Sinn argues that due to the intermittency of wind and solar power, buffers are needed. He investigates the potential of pumped-storage plants, also in an international context, including grid expansions. Sinn is not overly optimistic on these options and suggests reconsidering nuclear and replacing coal plants by gas fired electricity plants.

Three papers are directly concerned with the third challenge and in particular the technological changes that are needed to make possible the transition from fossil fuel to renewable energies. Corrado di Maria and Sjak Smulders challenge in their analysis "A paler shade of green: Environmental policy under induced technical change" that development of cleaner technologies decreases abatement cost or that policies directed at this type of innovation lower the cost of compliance by private firms. They discuss two mechanisms to illustrate this point. First, if aggregate pollution decreases, firms benefit if pollution poses a negative externality. However, individual firms do not take this externality into account when making their decisions and might decide to produce and pollute more. Moreover, the green investment decisions of firms may, in a general equilibrium context, prevent other beneficial investments. The main 
message is that in the design of policy what counts is the interplay between innovations, production externalities and the degree of complementarity of capital and technology.

There exists general agreement that a transition to a clean economy has to be made and that carbon taxation is an efficient instrument to achieve this. However, such a policy is costly and may be difficult to implement from a political perspective. Subsidies on clean technology might serve as an alternative, but of course these need to be financed by public means. In their paper "Dirty history versus clean expectations: Can energy policies provide momentum for growth?” Lucas Bretschger and Andreas Schaefer contribute to the debate. They consider a model where multiple equilibria exist with different characteristics with respect to greenness. It is shown that for the equilibrium selection expectations of the economic agents play a crucial role, together with economic history. Economic policy may provide momentum to make the transition to the superior green equilibrium.

Technical change in backstop technologies is central in the analysis of the distributive effects of alternative policies in the contribution "Balancing the carbon budget for oil: The distributive effects of alternative policies" by Carolyn Fischer and Stephen Salant. These alternative policies include cutting the cost of clean substitutes for fossil fuel and raising the carbon tax in regulated regions. The effect of reducing the cost of the backstop is that high-cost fossil fuels will not be extracted, which helps to keep emissions within the carbon budget. They calibrate their model with five different types of oil. They argue that a global carbon tax is a least-cost solution from which, however, non-regulated consumers benefit more due to lower energy prices. This is closely related to the concept of carbon leakage. They also expect that a global carbon tax needed to do the job cannot be implemented given the income differences across countries and therefore make a strong case for technology improvements which are of interest to both poor and rich countries.

Of course, these papers only touch on some of the challenges mentioned above. The field of climate change economics is very much alive. We think there are at least two further challenges for future research. One is that the time scales for damages to the national environment and the economy to occur are very long, varying from a half to many centuries. This makes it politically very difficult to convince current generations to make sacrifices when switching from cheap and abundant coal, oil and gas to solar, wind and other renewable energies, since the curbing of damages may take two to eight generations ahead, especially if future generations are expected to be richer and benefit from more advance technologies. Some of these problems might be overcome by climate-debt or climate-pension deals as state pensions are nowadays paid for by the current young and thus work in a mirror way to climate policy. More work is needed on such intergenerational deals. 
The other challenge for future research is that the problem of climate change is fraught by a whole range of economic and climate uncertainties, both of the traditional and the Knightian type. Furthermore, many of these risks are not normally distributed and the density functions describing them are skew or have fat tails. Policy makers also have to deal with the risks of irreversible tipping points such as the melting of the Western Antarctic and Greenland ice sheets or the reversal of the Gulf Stream, which typically increase with temperature. The optimal price of carbon has to factor in all these risks, especially those associated with future shocks to consumption growth, to the atmospheric carbon stock, the climate sensitivity and damages. The most important risk is perhaps the one to do with subjective model uncertainty including how to deal with climate deniers. Much more empirical work must be done to identify the risks and uncertainties involved in fighting global warming and on what these risks and uncertainties mean for climate policy.

\section{References}

Borissov, K., Pakhnin, M., Puppe, C., 2017. On discounting and voting in a simple growth model. Eur. Econ. Rev. 94, 185-204.

Brock, W., Xepapadeas, A., 2017. Climate change policy under polar amplification. Eur. Econ. Rev. 94, 263-282.

Harstad, B., 2012. Buy Coal! A Case for Supply-Side Environmental Policy. J. Political Econ. 120(1), 77-115.

Lechthaler, F., Vinogradova, A., 2017. The climate challenge for agriculture and the value of climate services: Application to coffee-farming in Peru. Eur. Econ. Rev. 94, 45-70.

Nordhaus, W., 2015. Climate Clubs: Overcoming Free-Riding in International Climate Policy. American Econ. Rev. 105(4), 1339-1370. 